\title{
EPISTEMOLOGIAS E DESCOLONIZAÇÃO NA AMÉRICA LATINA: COMPREENDENDO AS MEDIAÇÕES E A TRANSMETODOLOGIA COMO PRÁXIS EPISTÊMICO-METODOLÓGICAS TRANSFORMADORAS
}

\author{
Eloy SANTOS ViEIRA* \\ Universidade do Vale do Rio dos Sinos, Brasil \\ eloy.jor@gmail.com \\ LEILA LIMA DE SOUSA** \\ Universidade Federal do Maranhão e Universidade \\ do Vale do Rio dos Sinos, Brasil \\ leilasousa.pi@gmail.com
}

Recibido: 5/12/2019/Aceptado 16/4/2020

doi: $10.26439 /$ contratexto2020.n033.4791

Resumo. Nosso objetivo é debater sobre a importância da descolonização do pensamento comunicacional para a Comunicação na América Latina. Assim, levantamos algumas provocações capazes de contribuir para uma discussão mais complexa sobre outras epistemologias e metodologias que emerjam de realidades originais e autóctones e de contextos concretos que nos afetam, mas que nem sempre são observadas sob critérios cabíveis à nossa história e à nossa realidade empírica. Desta forma, acreditamos que conseguiremos dar um protagonismo maior aos processos sociais circundantes e não ficaremos restritos a perspectivas binárias que reconhecem apenas a recepção e/ou produção. Para isto, realizamos aproximações e confrontações teóricas sobre a construção do pensamento ocidental e suas epistemologias para, então, discutir sobre a constituição das Ciências Sociais e da Comunicação enquanto campo e de sua trajetória dentro da América Latina. Ao fim, propomos uma aproximação a partir de uma proposta de operacionalização das mediações e da perspectiva transmetodológica que se

\footnotetext{
* Doutorando em Ciências da Comunicação (Universidade do Vale do Rio dos Sinos, Brasil), Mestre em Cultura, Economia e Políticas da Comunicação (2016) pela UFS. https://orcid.org/0000-0003-4989-8125

** Docente da Universidade Federal do Maranhão - Campus Imperatriz. Doutoranda em Ciências da Comunicação (Universidade do Vale do Rio dos Sinos, Brasil). https://orcid.org/0000-0003-2335-0858
} 
constituem como dois potentes caminhos para pensar de forma concreta as configurações metodológicas a partir da América Latina.

Palavras-chave: epistemologia; comunicação; mediações; perspectiva transmetodológica; América Latina

\section{EPISTEMOLOGÍAS Y DESCOLONIZACIÓN EN LATINOAMÉRICA: ENTENDIENDO LAS MEDIACIONES Y LA TRANSMETODOLOGÍA COMO PRAXIS EPISTÉMICO-METODOLÓGICAS TRANSFORMADORAS}

Resumen. Nuestro objetivo central es discutir la importancia de la descolonización del pensamiento comunicacional para la Comunicación en Latinoamérica. Para eso, proponemos algunos postulados capaces de contribuir para una discusión más compleja acerca de otras epistemologías y metodologías que emergen de las realidades originales y autóctonas, y de contextos concretos que nos afectan, pero que no siempre son observados bajo criterios que dialogan con nuestra historia y nuestra realidad empírica. Así, esperamos priorizar una perspectiva en la que los procesos sociales circundantes sean protagonistas de una construcción que no se limita a perspectivas bipolares que reconocen solamente la recepción y/o la producción. Por consiguiente, realizamos aproximaciones y confrontaciones teóricas acerca de la construcción del pensamiento occidental y sus epistemologías, luego discutimos acerca de la constitución de las Ciencias Sociales y de la Comunicación como campos y su trayectoria dentro de Latinoamérica. Para finalizar, proponemos una aproximación desde una propuesta de operacionalización de las mediaciones y de la perspectiva transmetodológica que se constituyen como dos potentes caminos para pensar, concretamente, las configuraciones metodológicas desde un punto de vista latinoamericano.

Palabras-clave: Eeistemología; comunicación; mediaciones; perspectiva transmetodológica; América Latina 


\title{
EPISTEMOLOGIES AND DECOLONIZATION IN LATIN AMERICA: UNDERSTANDING THE MEDIATIONS AND TRANSMETHODOLOGY AS A TRANSFORMATIVE EPISTEMIC-METHODOLOGICAL PRAXIS
}

\begin{abstract}
The main objective of this paper is to discuss the importance of decolonization of communicational thinking for communication in Latin America. Thus, we propose some points to conduct a more complex discussion on other epistemologies and methodologies that emerge from original and autochthonous realities, as well as from specific contexts that affect us but are not always observed under appropriate criteria regarding our history and our empirical reality. Therefore, we aim to give priority to the surrounding social processes for them to have a leading role over restricted bipolar perspectives that only recognize reception and/or production. We also make some theoretical approaches and confrontations to the construction of western thinking and its epistemologies. Additionally, we discuss the setting-up of social sciences and communication as fields, and their trajectory within Latin America. Finally, we suggest an approach to operationalize the mediations and transmethodological perspective, which are two powerful ways to specifically think about the methodological configurations from a Latin American point of view.
\end{abstract}

Keywords: epistemology; communication; mediations; transmethodological perspective; Latin America 


\section{INTRODUÇÃO}

"Qual o lugar da ciência?" Esta pergunta genérica é mais que um simples questionamento. Ela é uma provocação que nos serviu de ponto de partida para uma reflexão epistemológica que, apesar de estar sempre posta, nem sempre recebe a devida atenção. Se partirmos da própria etimologia da palavra, ficam evidentes as intersecções entre nossa prática científica e o pensamento filosófico. Por isso, Japiassu (1977) salienta a centralidade que a ciência ocupa na nossa sociedade contemporânea e questiona o que, de fato, é considerado Epistemologia: "O lugar que a ciência ocupa na sociedade atual é tão grande e tão significativo que ela se torna uma das mais importantes atividades humanas a ponto de constituir-se mesmo numa das formas específicas da existência moderna do homem" (p. 144).

A Epistemologia, de uma maneira geral, se ocupa de estudar a constituição do conhecimento, compreendendo seus "princípios, as hipóteses e resultados" (Japiassu, 1977, p. 38). "Diz respeito à filosofia do conhecimento e à teoria do conhecimento, cujas fronteiras não são facilmente reconhecíveis" (Cassirer, 1993, p. 5). Muito além dos resultados, se ocupa dos processos para chegar ao conhecimento. Podemos dizer que a Epistemologia é atravessada por todas as dimensões do conhecimento e não existe separada dessas dimensões, não pretendendo teorizar sobre qual o conhecimento que deve ou não ser considerado válido.

Distante de dogmas, a Epistemologia se propõe problematizá-los e a quebrar mitos na produção científica. Assim, é marcada pelas rupturas com o senso comum acadêmico, o patrimonialismo, o patriarcalismo, os dogmatismos. Ao se valer da ideia do conhecimento como um processo, também chama a atenção para a necessidade de observá-lo como uma construção coletiva, condicionada pelo contexto sociocultural (Japiassu, 1977; Cassirer, 1993; Norris, 2007; Maldonado, 2008).

É nessa perspectiva de entender o conhecimento científico como resultado de sucessivas experimentações e testes, que podem romper ou dar continuidade aos paradigmas que foram construídos, que a abertura ao erro se faz necessária. Para a construção de novas dinâmicas de produção do conhecimento, o erro é fundamental porque dá as bases para a confrontação e para a reflexão da ciência, de modo que possamos fugir da busca incessante de um conhecimento verdadeiro, que não existe, e passemos a valorizar o processo.

Assim, formular teorias e paradigmas de modo constante nada mais é que buscar uma vigilância epistemológica (Bourdieu, Chamboredon e Passeron, 2010, p. 23) ao fazer ciência. Ser vigilante não quer dizer esconder os erros, mas usá-los como um caminho problematizador, reflexivo e que se propõe sistematizar as intuições e separar as induções das aparências e das crenças naturalizadas. 
Refletir criticamente sobre a prática científica tem como um dos primeiros caminhos romper com o senso comum acadêmico, que é visto como um entrave na construção do conhecimento (Japiassu, 1977; Maldonado, 2008). Desconstruir dogmas e ideias baseadas no teoricismo e no cientificismo é um dos caminhos para uma ciência que foge aos sensos comuns acadêmicos, ao engessamento e à falta de criticidade e de reflexão ao fazer ciência e a produzir conhecimento.

Se partimos da premissa de Morin (2008), percebemos que as relações e os contextos passam a balizar novas discussões acerca da produção do conhecimento e do desenvolvimento científico, e que lidar com a natureza de conhecimentos relativos a um determinado contexto histórico é o tipo de tarefa pertinente, exatamente, às Ciências Sociais. É a partir delas, também, que a passagem da crença à cultura torna-se evidente, por meio do reconhecimento delas enquanto ciências propriamente ditas, como veremos adiante.

\section{DA CRENÇA À CULTURA: UMA REFLEXÃO EPISTEMOLÓGICA SOBRE 0 DESENVOLVIMENTO DAS CIÊNCIAS SOCIAIS}

Para Bourdieu et al. (2010), a institucionalização dos métodos e técnicas de pesquisa específicos para as Ciências Sociais tiveram função fulcral para a constituição da área. Ao mesmo tempo que critica o Positivismo, destaca as imbricações entre metodologia e epistemologia, algo que Wallerstein (1996) também reconhece e defende pelo modo como isso se refletiu nas Ciências Sociais de forma particular a ponto de essas romperem com os paradigmas das Ciências Naturais conforme descreve em boa parte de sua obra.

Wallerstein (1996), que trata da construção histórica das ciências do século XVIII até o final da $2^{\text {a }}$ Guerra, defende que os velhos paradigmas utilizados para balizar o desenvolvimento de praticamente todas as ciências nunca funcionaram ou deixaram de funcionar, em especial nas ciências sociais onde as fronteiras entre as áreas são bastante nebulosas e a divisão interna em disciplinas é algo meramente administrativo na prática.

Depois desses primeiros rompimentos epistemológicos com outros campos, as Ciências Sociais ainda apresentaram mais alguns processos internos. Alguns deles são propostos por Haller (1990) e Santos (2006) que demonstram algumas formas de rompimento com os paradigmas questionados e apresentados por Wallerstein (1996).

Ambos seguem defendendo que a contextualização é algo inerente às Ciências Sociais, mas fazem isso por caminhos diferentes. Enquanto Haller defende que elas deveriam adotar o mesmo método da filosofia sem separação entre o empírico e o transcendental, Santos defende a contextualização a partir da cultura que, segundo ele, foi negligenciada pelos paradigmas descendentes das ciências naturais.

Em complemento a Haller (1990), Popper (1975) lembra que a Filosofia sempre fez parte do desenvolvimento humano ao longo da história, nem que fosse como algo 
meramente latente no cotidiano. Na ciência, ter problema que demande explicações é o objetivo, diferente do senso comum, onde o problema é algo indesejado

... parece que, quando falamos de ciência, sentimos, mais ou menos nitidamente, que há alguma coisa característica da atividade científica; e como a atividade científica tem muito bem o aspecto de uma atividade racional, e como uma atividade racional deve ter alguma meta, a tentativa de descrever a meta da ciência pode não ser inteiramente fútil. Sugiro que a meta da ciência é encontrar explicações satisfatórias de qualquer coisa que nos impressione como necessitando de explicação. (Popper, 1975, p. 180)

Na outra ponta, em complemento à proposta de Santos (2006), é possível perceber o movimento de Habermas ao defender sua Teoria da Ação Comunicativa na qual propõe soluções para sair de um paradigma centrado no sujeito por um centrado na razão comunicativa e assegura que, apesar disso, não propõe um retorno ao purismo da razão pura (2000, p. 420). Para isso, reconhece a centralidade da cultura através da defesa da linguagem que, para ele, deve ser estruturada a fim de que a racionalidade dependa diretamente do contexto sociocultural, uma vez que ele a enxerga ancorada nas dimensões prática-moral e estética-expressiva e não como mera dimensão cognitiva-instrumental.

Podemos perceber, portanto, que a trajetória da humanidade é indissociável de sua própria produção de conhecimento. Produção esta que está sempre em construção através da linguagem, mas que se efetiva como prática a partir da cultura e da comunicação, aspectos dos quais devemos nos centrar daqui por diante para chegar ao cerne da nossa discussão.

\section{DA CULTURA À COMUNICAÇÃO}

É possível verificar o movimento do conhecimento mencionado anteriormente em vários países, porém é na França que Mattelart e Mattelart (2004) percebem-no e o descrevemno com afinco. A trajetória da Comunicação deriva diretamente da questão da linguística e do discurso.

Foi, ainda nos anos 1960, que a abordagem transdisciplinar da cultura com um cunho semiológico, herdada diretamente de Barthes, deu origem ao Centro de Altos Estudos de Comunicação de Massa (Cecmas). Mas é só na década seguinte que a Comunicação ganhou espaço. Mesmo negligenciando aspectos históricos e até econômicos, os autores reconhecem a importância dela na reestruturação social, econômica e política que o país passava naquele momento.

O campo das mídias continua sendo o campo do lazer ao passo que a evolução tecnológica faz da comunicação e da informação um dos eixos maiores em torno do qual se reorganizava o conjunto das estruturas da sociedade francesa e das relações internacionais. (Mattelart e Mattelart, 2004, p. 50) 
E complementam dizendo que: "[as] importantes decisões não estão mais restritas a esfera Estado-nação, mas envolve as tecnologias de comunicação e de informação como dispositivos estruturadores" (Mattelart e Mattelart, 2004, p. 183). Por isso, ao relacionar comunicação e desenvolvimento tecnológico, Muniz Sodré (2016) advoga acerca da importância de se analisar e descrever os processos de comunicação eletrônica com a epistemologia, pois, para ele, atualmente a comunicação eletrônica é epistemológica por excelência, porque ela já está inserida em uma fase do capital intitulada por ele como "turbo-capitalismo".

Dentro de toda essa lógica turbo-capitalista, a Comunicação está vinculada diretamente a uma ordem social e financeira que a torna um mero valor fictício e o poder do capitalismo é o poder das finanças (Sodré, 2015).

Assim, o turbo-capitalismo é diretamente responsável pelo fim das barreiras geográficas a partir das estruturas de mídia, tecnologia e comunicação globais. Capazes de proporcionar uma passagem da comunicação unidirecional e heterogênea, para uma operacionalizada a partir do conceito de pointcast. É sob as lógicas da comunicação eletrônica que o espaço público - antigamente ampliado midiaticamente - torna-se fragmentado pela mídia eletrônica: a internet. (Sodré, 2015).

Desta forma, mais do que nunca, a comunicação assume uma centralidade, não só na vida cotidiana, mas também na pesquisa com novos objetos a serem investigados, que pedem cada vez mais que a Comunicação reconheça nos meios de comunicação sua base empírica (Lima, 2000) como forma de diferenciar-se de outras ciências e garantir subsídios epistemológicos para a sua constituição enquanto campo científico.

Junto às tecnologias digitais e ao processo de digitalização, que se configuram como contextos potentes de construção de narrativas, as pesquisas contemporâneas em comunicação desenvolvem-se a partir estudos anteriores que tinham como foco a manipulação, persuasão, influência e as funções, para pensar nos diferentes e conflitantes contextos sociais que atravessam os sujeitos e às suas percepções dos usos dos meios. As discussões voltam-se, portanto, para a problematização dos receptores ativos no processo de comunicação, que selecionam, interpretam, produzem e distribuem conteúdos e mensagens, dotados de autonomia comunicativa e de habilidade de manusear mídias, a exemplo da internet.

Nos estudos contemporâneos, verifica-se certa abertura do campo que durante muito tempo se apoiou em pesquisas que visualizavam emissores e receptores em polos separados e com rígidas divisões. São revistas, também, as ideias sobre lógicas totalizadoras sobre o modo como cada sujeito se apropriava dos meios de comunicação e sobre os estudos focados no midiacentrismo, que dotavam a mídia de um superpoder de controle e manipulação (Rodrigo Alsina, 1995; Wolf, 2008; Martín-Barbero, 2008). 
Uma necessária abertura dos pesquisadores e das pesquisas no campo da comunicação revela ser preciso pensar em novas ideias que trabalhem a ruptura de paradigmas e que estejam focadas no contexto social, onde as interações acontecem (Rossetti, 2016).

\subsection{A Comunicação como campo}

Para falar de Comunicação, estabelecemos um importante e fundamental diálogo com a Cultura. É dessa imbricação que começam as discussões epistemológicas acerca da instituição da Comunicação enquanto campo. Eco (1984), quando traça essa mesma discussão acerca dos meios de comunicação, parte do conceito de cultura de massa para propor reflexões que abandonem as dicotomias que pairavam sobre a Comunicação desde suas gêneses arraigadas nas perspectivas administrativas e críticas, uma discussão que segue presente no campo da Comunicação apesar do passar dos anos, mas, que, segue sendo um importante ponto de debate, na sua visão:

0 apocalipse é uma obsessão do dissidente, a integração é a realidade concreta dos que são não dissidentes. A imagem do Apocalipse surge da leitura de textos sobre a cultura de massas, a imagem da integração emerge da leitura de textos da cultura de massas. Mas, até que ponto nós não nos encontramos diante de duas vertentes de um mesmo problema, e, até que ponto os textos apocalípticos não representam o produto mais sofisticado que se oferece ao consumo das massas? Neste caso, o binômio 'apocalípticos e integrados' não daria conta da oposição entre as duas perspectivas. (Eco, 1984, p. 13, tradução nossa)'

Rossetti (2016), que trata propriamente da fundação da "Teoria da Comunicação" enquanto disciplina, faz um balanço entre as perspectivas críticas e as funcionalistas e acaba complementando a discussão travada por Eco (1984) anteriormente. A autora levanta a bandeira de que, no final das contas, as dicotomias entre "apocalípticos e integrados" não passam de falácias, uma vez que são olhares complementares sobre os mesmos aspectos da Comunicação:

Tanto a Teoria da Comunicação Funcionalista quanto a Teoria da Comunicação Frankfurtiana são consideradas fundadoras desse esforço teórico específico para compreender o que é comunicação... Essas duas escolas possuem quase um século de pesquisa e teorização sobre o fenômeno da comunicação. Frente às profundas e velozes transformações sociais pelas quais o mundo passou neste último século, essas Teorias da Comunicação fundadoras tiveram que adaptar

1 Do original: "El Apocalipsis es una obsesión del dissinter, la integración es la realidad concreta de aquellos que no disienten. La imagen del Apocalipsis surge de la lectura de textos sobre la cultura de masas; la imagen de la integración emerge de la lectura de textos de la cultura de masas. Pero, ¿hasta qué punto no nos hallamos ante dos vertientes de un mismo problema, y hasta qué punto los textos apocalíticos no representan el producto más sofisticado que se oferece al consumo de masas? En tal caso, la fórmula 'apocalípticos e integrados' no plantearía la oposición entre dos actitudes" (Eco, 1984, p. 13). 
e atualizar seus conceitos originais de comunicação. Então, necessariamente ocorreram mudanças no interior dessas duas abordagens teóricas no que diz respeito a sua concepção de comunicação e seu posicionamento no interior da pesquisa social visto que o próprio fenômeno investigado estava em constante modificação. (Rossetti, 2016, p. 2)

Saindo dessa perspectiva dicotômica, Wolf (2008) e Rodrigo Alsina (1989) trazem propostas mais abrangentes e mais ou menos complementares acerca da constituição do campo da Comunicação até a atualidade. 0 primeiro está preocupado com uma organização cronológica, pois começa das gêneses das teorias críticas e da pesquisa administrativa e chega até questões mais contemporâneas que pegam inspiração nas teorias do jornalismo e na sociologia da Comunicação e a reflexão sobre as compreensões e os usos do termo "cultura de massa". É neste último ponto que eles se encontram, uma vez que Rodrigo Alsina (1989) discorre sobre a constituição da Comunicação a partir da aproximação com as ciências sociais.

Wolf (2008) traz como elemento fundamental para problematizar a construção e a abertura do conhecimento no campo da comunicação, questionamentos sobre cultura e comunicação de massa. Segundo ele, o termo "sociedade de massa" é um guarda-chuva que muitos teóricos utilizam de maneira conservadora, que veem a "massa" apenas como um resultado da industrialização crescente e das novas dinâmicas sociais vivenciadas com o melhoramento dos transportes e a urbanização das cidades.

Mas, para além desta visão quase maniqueísta, o autor complexifica um pouco mais o debate quando afirma que "massa" seria uma nova forma de organização social de sujeitos. Ele reconhece que os distanciamentos físicos, espaciais, simbólicos e culturais são os que tornariam de fato essa "massa" suscetível à manipulação dos meios de comunicação.

É necessário destacar que há muitos desencontros sobre os significados de cada um dos termos (cultura de massa, sociedade de massa, indústria cultural) e se partimos da ideia de cultura como algo dinâmico, moldado e construído pelas relações que o homem estabelece com o mundo, é necessário que tais termos sejam utilizados com o devido cuidado e reflexão.

Diante de tantas discussões sobre a fragilidade do conceito de cultura/sociedade de massa, podemos dizer que a concepção de massa como foi entendida em tempos passados está superada, já que na contemporaneidade não parece frutífero problematizar de que modo as novas tecnologias e novas ideias do social possibilitam outras discussões sobre a "massa" (Rodrigo Alsina, 1995).

Pensando nisso, ainda na década de 1950, Rodrigo Alsina (1989) começou uma busca por "uma ciência própria da comunicação a partir de correntes integradoras de distintas disciplinas" (p.13) que poderia responder de forma mais completa a essas provocações. 
Assim, a Comunicação passou a tornar como próprios os objetos e técnicas de pesquisa antes compartilhados pelas diversas ciências sociais especialmente aquelas de cunho mais cultural e, desta forma, passou a se beneficiar diretamente deste "entre-lugar" entre as outras ciências.

Rodrigo Alsina (1989) entende a comunicação como uma "ciência-encruzilhada". A ideia pode ser vista como algo enriquecedor, uma vez que torna a Comunicação plural por natureza, mas também como algo enfraquecedor, pois ao se aproximar de tantos outros campos, a Comunicação pode acabar por não conseguir formar seu campo próprio. Uma dicotomia que, assim como os apocalípticos versus integrados, ainda pauta boa parte das discussões epistemológicas até hoje.

$\mathrm{Na}$ contramão destas dicotomias, atualmente outros autores vêm travando discussões epistemológicas pontuais acerca da construção do campo da Comunicação. Em Peruzzo (2016); Vieira, Coêlho e Marques (2016) isso fica evidente quando eles discutem sobre novas abordagens dentro do campo da Comunicação e trazem tensionamentos importantes como é o caso da "pesquisa ação", que traz questões importantes sobre o envolvimento de pesquisador com sua investigação e a possibilidade de novos olhares sobre subjetividades que vão surgindo a partir de correlações advindas do nosso contexto atual.

Assim, a partir dos estudos da linguagem e da cultura, a Comunicação lança mão de seus primeiros passos para constituir-se enquanto campo e ter base para conquistar espaço enquanto ciência quando se arriscam os caminhos iniciais para discussões epistemológicas que questionem sua própria constituição, como pudemos verificar através dos movimentos apresentados.

No entanto, estas discussões, apesar de terem feito passagem para incorporar aspectos mais subjetivos e/ou relativos à cultura, por vezes não privilegiavam discussões fora dos contextos hegemônicos, exatamente os mesmos onde a Comunicação ganhou suas primeiras raízes, sejam elas na Europa com as perspectivas críticas ou nos Estados Unidos com a pesquisa administrativa. Assim, o que propomos aqui é finalmente chegar numa discussão capaz de apontar questionamentos iniciais e incitar provocações a partir de um olhar fora desses eixos e que possa contribuir para uma discussão mais complexa da(s) epistemologia(s) da Comunicação.

\section{CONTRIBUIÇÕES DA AMÉRICA LATINA OU POR QUE PRECISAMOS DE OUTRAS EPISTEMOLOGIAS?}

"A guerra é a origem de tudo". Ao invocar a famosa citação de Heráclito sobre a gênese da história na Grécia Antiga, Dussel (1977, p. 8-10) correlaciona a geopolítica e a filosofia para então defender o que dá nome à sua obra Filosofia da Libertação na América 
Latina. Desta forma, consegue explicitar as relações entre dominantes (Europa e Estados Unidos) e dominados (América Latina) dentro dos âmbitos da filosofia, a partir de questões que circundam o desenvolvimento conflituoso dessa região que se dá. Sobretudo, a partir da noção de cultura, conforme o ilustrado com propriedade por Rincón (2016) na metáfora sobre o que ele chama de "culturas bastardas":

Temos uma só mãe que é a cultura local de onde somos - chilangos, caribenhos, cordobeses: essa é nossa localidade de significação e narração, nosso lugar cultural de enunciação e destino. $E$ temos muitos pais dos quais fomos formados (mesmo que sem nos darmos conta). Um pai maldito se chama Televisa no México ou Globo no Brasil; mas também temos outros pais que se chamam 'Hollywood'; e outros pais que se chamam culturas tradicionais populares musicais e religiosas; $\mathrm{e}$ mais pais esclarecidos e da academia; e também temos pais astecas, maias, incas; e somos filhos de redes populares do digital e da midiática, e das indústrias do espetáculo; e também filhos da zombaria, da aposta, do humor, da irreverência, da ironia. Temos muitos pais (populares, estéticos, narrativos), e por isso não somos puros e essencialistas, porém tampouco interculturais... (pp. 37-38)

Com este excerto, fica evidente que Rincón atualiza uma discussão mais que pertinente nas "arenas culturais". Enne et al. (2018) apontam que ao considerar as culturas populares como "bastardas", o autor colombiano estaria acionando diretamente os embates travados por outros pesquisadores do Sul global como Nestor García Canclini e suas culturas híbridas, Jesús Martín-Barbero e as mediações e a de Homi K. Bhabha com a perspectiva intersticial de entre-lugar (Bhabha, 1998, p. 69).

Tomamos estas provocações como ponto de partida para convocar mais algumas formas "bastardas" de ver o mundo. Boaventura de Sousa Santos pode ser interessante como ponto de partida neste ponto devido à sua proposta das "epistemologias do Sul", que prevê a necessidade de se pensar além da Europa a partir de uma concepção metafórica que coloca as epistemologias do Sul como uma expressão da diversidade epistêmica global (Santos, 2006).

Para o autor supracitado, o Sul, além de ser definido geopoliticamente como o conjunto de países que foram alvos do colonialismo europeu desde o século XV e que, por isso, não foram capazes de alcançar o mesmo patamar de desenvolvimentos social, político e econômico que aqueles do Norte, é também um campo vivo de desafios epistêmicos como a mitigação de danos e impactos históricos causados por esses processos históricos (Santos, 2006, p. 190-191).

Por isso, defendemos que as "culturas bastardas" coadunam diretamente também com a proposta de "ecologia dos saberes" (Santos, 2006) uma vez que o conhecimento, assim como a cultura, não deve ser visto como algo absoluto, mas sim como um entrelugar intelectual capaz de agregar novos conhecimentos sem esquecer os autóctones, ou seja, ter a capacidade de extrapolar as narrativas de subjetividades originárias e 
focar nos momentos ou processos que são produzidos a partir das diferenças culturais (Bhabha, 1998, p. 20).

Morawicki (2016) também é outro autor que defende esse pragmatismo quando o assunto é produção de conhecimento na América Latina. A partir de estudos na interface entre Comunicação e Educação na Argentina, ele defende que este movimento epistêmico-cultural seja feito também a partir de uma articulação direta entre as práticas sociais e as metodologias.

Para o autor, este movimento consiste em promulgar uma espécie de "anti-teoria" de forma bastante pragmática porque proporcionaria uma relação direta entre linguagem, experiência e práxis. Isto, para ele, é um grande ganho para a América Latina enquanto espaço de discussão epistemológica da Comunicação e da Educação.

0 interesse por continuar a tradição latino-americana que conecta a produção teoria com as práticas é, portanto, relevante para os campos da Comunicação e da Educação uma vez que é um espaço fundamentalmente constituído por práticas e que aspira a transformação dos modos hegemônicos de se fazer educação e comunicação (Morawicki, 2016, p. 356)2.

E, retomando Santos (2006), é possível ter nele uma perspectiva que pode ser vista como uma espécie de contra epistemologia que reconhece a pluralidade de saberes (incluindo os não-científicos) em detrimento de uma epistemologia geral. Este pensamento pode ser aproximado ao que é proposto por Maldonado $(2008$, p. 40 ) quando fala sobre as "epistemologias como dimensões transformadoras" abrindo caminho para a valorização e o respeito de diversidades e diferenças e também para conhecimentos outros, que estão além da Europa e dos centros universitários, que se efetivam nos conhecimentos ancestrais, nas artes, na música e nas culturas.

Mas o que teria exatamente de tão diferente na América Latina capaz de gerar "culturas bastardas", "anti-teorias" ou "epistemologias do Sul" conforme apontadas aqui? É numa tentativa mais descritiva que esclareceremos a partir do próximo ponto.

\subsection{Veias abertas da América Latina}

Para trazer à tona questões sobre a América Latina, visitamos as famosas "veias abertas" de Galeano (1978):

É a América Latina, a região das veias abertas. Desde o descobrimento até nossos dias, tudo se transformou em capital europeu ou, mais tarde, norte-americano, e

2 No original: “El interés por continuar la tradición latinoamericana que conecta la producción teórica con las prácticas es, por tanto, relevante para el campo de Comunicación y Educación, ya que es un espacio fundamentalmente constituido por prácticas y que aspira a la transformación de los modos hegemónicos de hacer educación y comunicación." (Morawicki, 2016, p. 356) 
como tal tem-se acumulado e se acumula até hoje nos distantes centros de poder. Tudo: a terra, seus frutos e suas profundezas, ricas em minerais, os homens e sua capacidade de trabalho e de consumo, os recursos naturais e os recursos humanos. (p. 5)

Da terra aos recursos humanos, a América Latina tem seu histórico completamente arraigado ao colonialismo. E isso não seria diferente dentro da Comunicação. Para tratar de algumas consequências práticas dessas "veias abertas" para a pesquisa em Comunicação na América Latina, trazemos Martín-Barbero, que, assim como Boaventura de Sousa Santos, e apesar das origens europeias, dedicou-se ao estudo das consequências das heranças colonialistas em diversos países, no caso dele, focado na realidade latino-americana a partir da Colômbia, onde foi radicado.

É no final dos anos 1980 que ele descreve o cenário latino-americano para a pesquisa em Comunicação. Em seu breve artigo sobre as dificuldades de se fazer pesquisa na América Latina, descreve um cenário hostil no qual diversos países ainda estavam passando por transições de ditaduras para democracias controladas e fortemente influenciadas pelo crescente neoliberalismo dos países desenvolvidos, o que acabava gerando um grande impasse entre o caráter internacional da estrutura econômica e o caráter nacional da esfera política.

Por isso mesmo, Maldonado (2013) lembra que:

O nosso habitat intelectual foi configurado em dinâmica e profunda inter-relação com as demandas econômicas, políticas, sociais e culturais das sociedades capitalistas, tanto na América Latina, quanto nos Estados Unidos e na Europa Ocidental. (p. 32)

Mais precisamente, nas palavras de Mignolo (2006, p. 313), é a partir da "colonialidade do poder" e da "colonialidade do saber" que se configuram as matrizes da produção intelectual na América Latina que é baseada numa construção colonial que subjuga os conhecimentos e saberes dos povos colonizados, numa hierarquia de poder em que os colonizadores situam-se e se auto-avaliam como produtores e detentores válidos do conhecimento.

Dialogando com Mignolo (2006), Piza e Pansarelli (2012) acredita que o conhecimento produzido na América Latina fundamenta-se em:

...aspectos epistêmicos coloniais, dentre eles o conhecimento fundado na relação sujeito e objeto, em que o objeto é subjugado pelo sujeito, assujeitado, portanto, a crença na superioridade da ciência e do saber ocidentais e no questionamento da existência de uma racionalidade para além da racionalidade forjada nas línguas maternas da Europa. (Piza \& Pansarelli, 2012, p. 31)

É pensando nessas categorias da colonialidade e de suas implicações, que se estabelece, portanto, a necessidade da descolonização epistemológica para que possamos ir 
além do que a Ciência Política ou as Relações Internacionais podem compreender como descolonização ${ }^{3}$. Trazendo novamente o pensamento de Dussel (1977) quando defende que toda teoria é política e de Martín-Barbero que complementa tanto a ele quanto a Galeano ao dizer que: "...a teoria é um dos espaços-chave da dependência" (MartínBarbero, 1988, p. 3, tradução nossa)", a descolonização do saber e do poder podem surgir a partir de rupturas teórico-epistemológicas, mas também das nossas identidades.

Compreendemos o processo de descolonização, portanto, como um processo de contraposição epistêmica, de desvinculação do genuíno ocidental, a partir da "pluridiversidade" (Mignolo, 2008, p. 300). Trata-se da tomada de consciência mestiça e do desenvolvimento de uma identidade política de resistência. A opção descolonial significa "aprender a desaprender", ressignificar narrativas, o processo de constituição dos sujeitos e a própria compreensão destes (Mignolo, 2008, p. 290).

No tocante à Comunicação, Torrico Villanueva, adiciona que no cenário latinoamericano temos possibilidades claras para além dos modelos ocidentais e colonizadores, especialmente diante das características de "caráter e potencial subversivo" (2016, p. 147) deste solo. Perspectivas apontadas também por Martín-Barbero (1988), Santos (2006) e Morawicki (2016), por exemplo, quando defendem a potência de extrapolar dimensões estritamente científicas e a possibilidade de deslocamentos maiores nos modos de se pensar a nossa realidade, ponto que vamos explorar um pouco mais adiante neste texto.

\subsection{Processos sociais e processos midiáticos: a importância de um olhar comunicacional para pensar epistemologias transformadoras}

Conforme foi apontado anteriormente, quando abordamos a pesquisa na América Latina, estamos tratando, ao mesmo tempo, de questões acadêmicas e políticas. Pensando nisto, recorremos inicialmente ao conceito de "processos midiáticos". Desta forma, esperamos garantir, primeiramente, uma perspectiva capaz de demarcar-se política e teoricamente no campo da Comunicação, como também pela ênfase das processualidades de fenômenos sociais midiatizados e não apenas suas estruturas.

Esperamos que este texto seja um exercício para a construção de uma racionalidade epistemológica da Comunicação que priorize os processos sociais circundantes e não ficar restrito a perspectivas bipolares e binárias que reconhecem apenas a recepção e a produção. Neste sentido, deslocamos e ampliamos a discussão e a reflexão sobre os

3 Para outros campos, o processo de descolonização está muito mais ligado ao processo de independência de diversos países durante o século XX e não necessariamente tem o mesmo caráter epistêmico que o termo carrega para outras áreas, como é o caso da Comunicação. Um exemplo disso está disponível na resolução da ONU sobre o seu Comitê Especial para Descolonização. Recuperado de: <https://www.un.org/es/decolonization/questions_answers.shtml>. Acesso em 18 de abril de 2020 . 
processos sociais e midiáticos para além dos dois polos citados, situando-nos diante de epistemologias amplas, diversas e transformadoras.

Em consonância com isto, segundo Gomes (2017), é preciso defender que nós, pesquisadores em Comunicação, podemos obter nesta perspectiva elementos essenciais para - a partir da mídia e de seus processos estruturantes e modos de produção - interpelar os inter-relacionamentos sociais e humanos contemporâneos (p. 38).

Para isto, os processos midiáticos podem ser o grande ponto de partida. Segundo Gomes, podemos entendê-los como um conjunto de práticas comunicacionais pertencentes ao campo das mídias que operam mediante dispositivos (TV, jornal, livro, fotografia, etc.) segundo diferentes linguagens (2017, p. 36).

Os processos midiáticos estão, pois, intimamente ligados às novas formas de organização social e às novas relações sócio-técnicas que se estabelecem e que originam novas experiências de midiatização que não se fecham em si próprios. Dialogam, ainda que de modo tentativo, com outros processos complexos de diferentes organizações, constituem-se de diferentes sistemas que têm como grande interlocutor o ambiente e atravessam a dimensão social (Gomes, 2017; Luhmann, 2005).

Braga (2006) complementa esse conceito, já que, segundo ele, devemos prezar por uma abordagem comunicacional transcendente, ou seja, uma abordagem que vá além da visão informacional e que não esgote a potencialidade dos processos midiáticos nos subsistemas de produção e recepção. Sua ideia é incorporar o que ele chama de "sistema de resposta social". Esse conceito complementaria a processualidade de midiatização social geral, uma vez que corresponde às interações sociais baseadas em produtos midiáticos.

Ao fazer esse movimento, o autor aponta, também, a necessidade de reconhecer a perspectiva das mediações de Martín-Barbero (2013). Segundo aquele, a noção operacionalizada pelo teórico espanhol radicado na Colômbia seria capaz de retomar o olhar comunicacional que mencionamos, ao trazer para o "sistema social de resposta" as bases do cotidiano e da cultura, quer dizer, para que seja possível compreender comunicacionalmente, devemos estar atentos ao contexto, isto é, a aportes pré e extramidiáticos, algo que fica mais evidente na última atualização de seu mapa (abaixo): 
TEMPORALIDADE

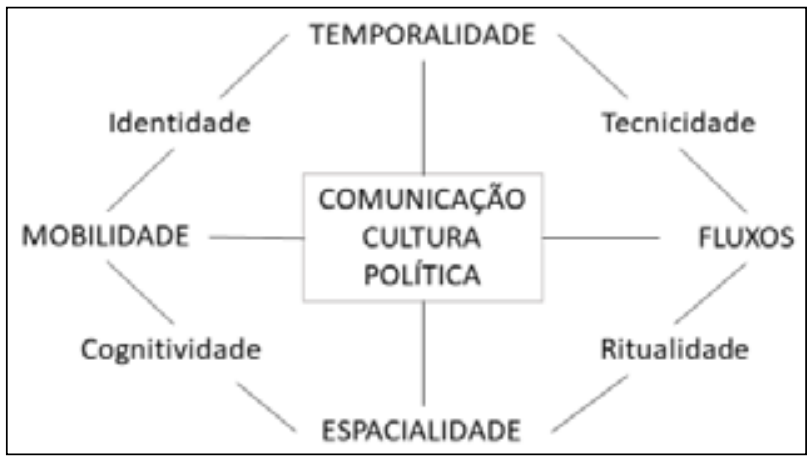

Figura 1. Proposta de atualização do mapa das mediações

Fonte: Lopes, 2018 (p. 19)

Esta proposta adaptada por Lopes (2018) acerca da operacionalização das mediações, atualiza as propostas iniciais de Martín-Barbero (1987; 1998) porque repensa a noção de comunicação na contemporaneidade como é possível perceber a partir dos seus eixos que estão focados, sobretudo, nas mutações da cultura (Temporalidade, Espacialidade, Mobilidade e Fluxos).

Assim, temos neste mapa noturno uma síntese atualizada e mais densa dessa proposta que, apesar de reconhecer o protagonismo da cultura, da comunicação e da política, não deixa para trás a importância de outras instâncias, especialmente, da sociedade através das práticas cotidianas destrinchadas a partir das interpelações entre o popular e o massivo.

Ao mesmo tempo, ele nos lembra de que, para que possamos lançar esse olhar comunicacional, é necessário fazer uma crítica às perspectivas tecnocentristas ${ }^{4}$ que colocam todas as discussões sob a égide da tecnologia ao invés de reconhecer os meios de comunicação como espaços-chave de condensação e intersecção de poder e cultura. Em suma, o que a proposta das mediações pretende é fazer uma passagem das estruturas aos processos. E é a partir disto que devemos balizar nosso olhar.

\subsubsection{O olhar barberiano e as mediações como possibilidade epistemológica}

Martín-Barbero (1988) torna-se central nessa discussão porque recontextualiza o trabalho do pesquisador das ciências sociais, especialmente daqueles que se dedicam à

4 Vale lembrar que ele aprofunda essa crítica às perspectivas tecnocêntricas no artigo "Razón Técnica y Razón Política: espacios/tiempos no pensados" quando aborda a ascensão simbólica da tecnologia em detrimento do esvaziamento da política a partir de uma abordagem heideggeriana (Martín-Barbero, 2004). 
comunicação de massa. De acordo com Zalamea (2008), juntamente com Rama e Canclini, Martín-Barbero faz parte da tríade responsável por repensar os Estudos Culturais na América Latina em sua $3^{\text {a }}$ fase, que se deu entre os anos 1980 e 1990 e que se caracteriza pela transversalidade epistemológica ao incorporar os aportes críticos, filosóficos e sociológicos e pelo aporte telescópico ao analisar o local dentro da perspectiva global a fim de gerar uma cartografia própria da América Latina.

Essas características são frutos do que Zalamea (2008 p.71) chama de "inteligência de trânsito", isto é, a capacidade que temos, enquanto conjunto de sociedades, de transitar entre diversas fronteiras. E este pode ser considerado o grande trunfo da pesquisa latino-americana uma vez que, ao contrário do que aconteceu na Europa, fomos capazes de transformar isso no grande combustível da nossa produção acadêmica ao invés de ver como um empecilho, pois, "ao situar-se num limite, numa margem, numa fronteira, a visão se multiplica: percebem-se vários territórios de uma vez só, várias interpretações, vários desafios e versões da mesma situação" (Zalamea, 2008, p. 71, tradução nossa). Ou seja, é partir das fronteiras que o centro é acessado em via de mão dupla e assim ocorrem as modificações nas perspectivas, nas recepções e na reelaboração e construção da cultura.

Retomando o pensamento Barberiano temos, na descrição da topografia movediça da América a partir do que ele mesmo chamou de "mapa noturno", demonstrações evidentes destas contradições da América Latina. Inclusive é a partir delas que o autor começa a indagar as estratégias de produção e comunicação massivas para propor uma inversão de olhares às "mediações", algo considerado até hoje como sua maior contribuição, não só a nível latino-americano, mas mundial. É exatamente o que aponta Schlesinger (2008) que destaca a importância de De os meios às medições - obra na qual estruturou toda essa proposta - nos países anglo-saxônicos. Para ele, foi a partir da proposta das mediações que temas como identidades, desterritorializações e descentramento cultural ganharam novo fôlego lá fora.

Ele lança outro olhar sobre o processo comunicativo a partir do conceito de mediação, muito bem discutido por Ollivier (2008). Segundo este autor, as mediações não têm apenas um conceito e é isso que as tornam ricas em possibilidades teórico-metodológicas. Para ele, as mediações podem ser pessoas, processos mentais (linguagem, imaginários, identidades, etc.) ou sociais, instâncias sociais ou até o próprio inconsciente que sejam capazes de "traduzir" as proposições de uma instância para a outra até chegarem numa espécie de acordo com o intuito de resolver conflitos interculturais (Ollivier, 2008, p. 122).

Sendo assim, o autor aponta que a riqueza das mediações está em conseguir criar uma teoria social da comunicação baseada no paradigma da comunicação capaz de abranger dimensões culturais, sociais, antropológicas e até linguísticas, pois reconhece que a mediação é uma instância prioritariamente cultural, a partir da qual o 
público produz o sentido do processo de comunicação. Portanto, ao apropriar-se disto, a pesquisa sobre os meios de comunicação de massa deve reconhecê-los como fenômenos que extrapolam as dimensões meramente comerciais e econômicas, também atuando nas dimensões culturais e sociais porque participam da criação de identidades e do sentido na vida cotidiana (Ollivier, 2008, pp. 127-128).

Ou seja, quando nos relacionamos com questões contemporâneas caras à globalização, como a crescente necessidade de se estudar processos locais com olhares globais, percebemos que os mediadores da comunicação têm tarefas cada vez mais imbricadas com processos que, assim como a globalização, são culturais, sociais, políticos e econômicos ao mesmo tempo. Desta forma, o papel destes mediadores é criar pontes entre as práticas sociais e culturais das audiências e os conhecimentos racionais da modernidade a fim de dar sentido ao cotidiano, às identidades de forma alinhada com o capitalismo e com a globalização, assumindo, portanto, tarefas que os mediadores políticos não conseguem mais dentro desse cenário.

A grande consequência da operacionalização do conceito de mediações para a pesquisa em Comunicação na América Latina é que, ao partir das culturas populares e do cotidiano das audiências, elas garantem as possiblidades de, simultaneamente, romperem com os dois grandes paradigmas do nosso campo.

Primeiramente, a ruptura (teórica) com o funcionalismo norte-americano por inverter o sentido do controle político do povo por parte da burguesia e dar uma nova roupagem à noção de cultura de massa, reconhecendo que as relações entre as culturas populares e massivas não são unívocas nem se dão em reprodução direta e que, portanto, são complexas de tal forma que demandam um olhar heterodoxo e uma epistemologia que fuja de maniqueísmos (Orozco e Miller, 2008).

Além disso, é devido a essa complexidade que a perspectiva nos permite abrir um flanco na teoria crítica, pois, ao inverter o sentido do controle político do povo por parte da burguesia e da noção de uma nova cultura de massa, Martín-Barbero reconhece, a partir das telenovelas como base empírica, que a mediação não é só o processo de recepção das mensagens, mas sim todo o processo de produção e difusão de bens simbólicos (Ortiz, 2008). Ou seja, ao partir das mediações ele não estaria pesquisando apenas acerca da recepção, mas sim sobre a relação paradoxal entre o popular e o massivo envolvidos num processo de midiatização.

Por isso, defende que as mediações estão dentro das indústrias culturais e são elas (jornalistas, produtores, autores, etc.) as grandes responsáveis por transitar entre as necessidades socioculturais, políticas e mercadológicas. Desta forma, toda a noção frankfurtiana de uma Indústria Cultural maniqueísta capaz de controlar as massas não condiz com a contemporaneidade, especialmente na América Latina e, assim, este paradigma epistemológico também é rompido. 
Não obstante, apesar de reconhecer o papel fundamental das mediações na pesquisa em Comunicação, especialmente no segmento voltado às audiências, é de fundamental importância garantir sua flexibilidade e adaptabilidade para que não se tornem antiquadas. Pensando nisto, Huertas Bailén (2015) propõe atualizações importantes ao mapa de Martín-Barbero (vide Lopes, 2018) que dão conta de algumas demandas contemporâneas que envolvem, sobretudo, o contexto das audiências na cultura digital.

Ao todo, a pesquisadora propõe que consideremos pelo menos mais cinco mediações. A primeira delas seria a "mediação individual" e interseccional". Segundo ela, o protagonismo do indivíduo deve ser levado em conta na pesquisa, mas tendo em vista sempre o paradigma da interseccionalidade que abarca questões de idade, gênero, origem cultural, dentre tantas matrizes de identidade. A segunda seria a "mediação contextual e institucional", que, diretamente, diz respeito aos protocolos de comportamento, ou seja, levar em conta as formas e os lugares (casa, trabalho, bar) em que o consumo midiático é realizado.

Enquanto essas duas primeiras mediações se preocupam diretamente com as audiências, as outras três se preocupam com o contexto, especialmente, com as possibilidades advindas da materialidade como é o caso da terceira mediação, a "programática", que diz respeito à hibridização das linguagens midiáticas e sua relação com os códigos de recepção marcados pelos diferentes gêneros midiáticos. A quarta mediação tem uma estreita relação com esta terceira e trata mais diretamente da questão tecnológica, ou seja, do agenciamento da tecnologia em relação à sociabilidade por meio dos suportes digitais. E, por último, a "mediação transcultural", que trata diretamente da relação entre Globalização e a capacidade de diálogo com "o outro".

Tendo em vista essa atualização proposta por Huertas Bailén (2015), passamos a discorrer, logo adiante, sobre a necessidade de a Comunicação também discutir sobre a centralidade do digital e dos processos de digitalização quando falamos de fenômenos culturais contemporâneos.

\subsection{Epistemologias transformadoras como perspectiva para entender a Comunicação na contemporaneidade}

A suposta "evolução tecnológica" e os embates entre os chamados "novos" e os "velhos" meios são temas muito caros à pesquisa contemporânea em Comunicação. Eles ganham destaque sob a alcunha do que se chama de "convergência", conceito capaz de concatenar, ao mesmo tempo, preocupações concernentes à tecnologia, à cultura e à comunicação. Para nós, obviamente, cabe o debate sob a ótica comunicacional, mas sem esquecer de todo o contexto por trás desse olhar.

É neste cenário em que a TV, considerada por muitos uma "velha mídia", assume, ao lado da internet e das chamadas "novas mídias", a centralidade em diversos processos 
que caracterizam a chamada "cultura da convergência", mas nem sempre essa relação foi harmoniosa, conforme relembra Huertas Bailén (2015):

Cada um dos meios de comunicação observou inicialmente a internet como uma inimiga perigosa. Podemos dizer que houve até um momento em que se pensou que tudo voltaria a ser como era antes, mas, finalmente, como era de se esperar, optaram por estarem presentes também no digital e buscar fórmulas para monetizar conteúdos. Acabaram vendo na rede, finalmente, condições de novas oportunidades ao invés de novos problemas. Mas, essa transição para o digital não está sendo nada fácil e, do ponto de vista social, a brecha digital indica que esse será um processo inevitavelmente lento. (versão kindle, tradução nossa)

Os objetos inseridos neste contexto tratam-se, necessariamente, de objetos situados no ponto de encontro entre a "cultura participativa" -descrita por Jenkins (2009) como constituinte essencial da cultura da convergência- e as indústrias culturais (Vieira e Silva, 2018, p. 317).

Umberto Eco (1984) já refletia sobre esses embates há algum tempo. Para ele, essa nova televisão esvazia-se politicamente e mistura ficção com informação a fim de sustentar uma suposta realidade em que só há lugar para ela mesma e seu próprio público. Já em Ladeira (2016) há uma visão bem menos fatalista acerca da TV do século XXI e muito mais técnica em relação à fluidez do conteúdo a partir das possibilidades de digitalização e, por conseguinte, do streaming, o que não significa dizer que seria menos crítica.

De acordo com o autor citado acima, não é só porque estamos lidando com uma evolução tecnológica que devemos deixar para trás o processo que nos levou à passagem do analógico para o digital.

No fundo, o que a alerta dele pode nos dizer é que o que precisamos fazer, enquanto pesquisadores em Comunicação, é reconhecer que há de fato uma valorização exacerbada da tecnologia e fazer um esforço epistemológico para vê-la na verdade como uma parte do que estamos estudando. Por isso, torna-se imprescindível, sob uma ótica comunicacional, pensarmos as configurações comunicativas nas mediações e focar no que as possibilidades técnicas implicam nas práticas comunicativas contemporâneas.

Acreditamos que epistemologias como dimensões transformadoras (Maldonado, 2008, 40) se fazem fundamentais para pensar as necessárias interrupções, continuidades e crises na prática científica e também na abertura dos diversos campos, sobretudo o da Comunicação, a outros saberes e novas perspectivas teóricas e práticas, entre os quais destacam as novas configurações dos sujeitos e de sua percepção dos meios diante de uma nova dimensão do social. A perspectiva transmetodológica (Maldonado, 2013) potencializa essas necessárias aberturas das ciências ao trocar a rigidez metodológica pela necessária experimentação e pelo diálogo e concretização das trocas transdisciplinares. 
Com base na discussão estabelecida acima, discorremos adiante sobre mais uma possibilidade além das mediações: a perspectiva transmetodológica.

\subsection{Perspectiva transmetodológica: epistemologias transformadoras pensadas desde as investigações em Comunicação}

A opção transmetodológica é, na verdade, um potente recurso e aporte metodológico para pensar e incitar a emergência de epistemologias transformadoras nas investigações em Comunicação. Mais do que isso, é também uma necessidade epistemológica que emerge da complexidade para se lidar com o cenário atual em que a cultura da informação, do conhecimento e da experimentação, transforma-se simultaneamente à tecnologia e ao processo de digitalização. Sendo assim, temos nessa opção norteadora alguns elementos-chave que nos ajudam a problematizar o processo de produção de nossas investigações comunicativas, a saber:

0 mais latente talvez seja exatamente a necessidade de uma epistemologia de continuidade em relação ao pensamento latino-americano e não necessariamente de ruptura com outras perspectivas críticas anteriores e colonizantes. Além disto, podemos compreender também que a pesquisa pode ter a finalidade de aprendizado, ou seja, a pesquisa torna-se práxis central para a aprendizagem humana, não necessariamente instrumentalizada. $E$, ao lado destes dois processos, é preciso também considerar o caráter complexo e multidimensional da construção do sujeito/pesquisador e do objeto de pesquisa.

A perspectiva transmetodológica nos estimula, então, a assumir uma decisão metodológica de compreender os sujeitos como sujeitos autônomos no processo de comunicação, na tentativa de romper com visões e discursos funcionalistas que os compreendem como receptores, usuários ou informantes. Assumimos e reconhecemos que os sujeitos são políticos, históricos, sociais, produtores de informação e de comunicação (Maldonado, 2013).

Além destes esforços, podemos destacar outros que concernem diretamente ao papel do sujeito/pesquisador e da construção da sua metodologia para estudar os contextos que envolvem os sujeitos, compreendendo que eles são também construídos entre um emaranhado de processos sociais e subjetivos.

0 que esperamos é assinalar que não há neutralidade nos procedimentos metodológicos que desenvolvemos (Alves, 2014), muito pelo contrário, a ideia é, assim como aponta Bonin, reconhecer que "a metodologia precisa se realizar em profunda articulação com a dimensão epistemológica para que possa se constituir como fabricação pensada dos objetos, dos processos e dos resultados do conhecimento" (2003, p. 27). Por isso,uma perspectiva histórica e contextualizante, se faz necessária. 
Segundo Maldonado, é impossível fundamentar um projeto de pesquisa qualquer sem um esforço sistemático de exploração, aprofundamento e compreensão dos tecidos de ideias, conceitos, raciocínios, argumentos, proposições, matrizes e modelos (2006, p. 286). Dessa maneira, compreendemos que a mirada reflexiva, histórica e contextualizante para as realidades concretas e para os cenários que atravessam os objetos, faz parte de uma tomada de decisão epistêmico-metodológica para a produção de investigações crítico-reflexivas. É diante desse deslocamento investigativo que discutimos nos próximos tópicos sobre as perspectivas transmetodológicas e as mediações como trilhas processuais para a configuração de novas e concretas epistemologias em solo latino-americano.

\subsubsection{Refletindo sobre a construção dos objetos sob a perspectiva transmetodológica}

No processo de produção da investigação e da nossa constituição como sujeitos, precisamos de olhares apurados e do entusiasmo pelo fazer. É, nesse sentido, que Bourdieu, Chamboredon e Passeron (2010), aproximando-se também do que propõe Cassirer (1993), nos alertam sobre a necessidade de aproximação com o objeto de pesquisa e a análise das afetações mútuas resultantes desse processo.

De acordo com a análise dos autores, não podemos desligar as nossas observações dos contextos sociais e históricos nos quais os sujeitos estão inseridos e da problematização teórica constante que nos auxiliará na construção do objeto dentro de uma realidade que the circunda. Cada objeto pressupõe técnicas diferentes de análise e de observação, esse é um processo necessário para fundamentar os deslocamentos teóricos-metodológicos que precisamos atravessar e também para refletir sobre a prática científica (Cassirer, 1993; Bourdieu, Chamboredon e Passeron, 2010).

Corroborando as ideias acima, Bachelard (2001) trabalha a necessidade da percepção de afetações e transformações mútuas entre sujeito e objeto como um caminho importante para a ruptura com o senso comum acadêmico (Japiassu, 1977, p. 70).

É assim também que Morin (2008) compreende sujeito e objeto como indissociáveis. Ambos são sujeitos históricos, detentores de saberes e de múltiplos referentes culturais e identitários. Sem perder de vista os valores, crenças, saberes e sensibilidades envoltas nesse processo, e sob um olhar transmetodológico, os sujeitos e os contextos concretos que os circundam não podem ser apenas entendidos como informantes ou como meros receptores, antes, precisam ser observados em sua autonomia constitutiva, como sujeitos de ação, de práxis, de problematização e de resistência, que possibilitam novos olhares e percepções para as dimensões teórico-metodológicas da pesquisa (Maldonado, 2008; Bourdieu, Chamboredon e Passeron, 2010; Peruzzo, 2016).

Diante do que foi proposto acima como um caminho para a análise crítica da postura do pesquisador e de suas práticas científicas, entendemos que o pesquisador precisa 
estar em contato com outros sujeitos, observando-os e sendo construído por eles, levando em consideração que cada sujeito é dotado de uma razão que não pode ser dissociada da sua natureza (Habermas, 2000).

No caso de nossas investigações em Comunicação, essa articulação deve ser realizada a partir do rompimento com perspectivas logocêntricas, priorizando o que Maldonado (2006) chama de "práxis teórica" ao nos apropriarmos, problematizarmos e reformularmos propostas, matrizes e modelos a partir dos estudos culturais e de recepção de raiz latino-americana.

Com isto, esperamos também nos posicionarmos criticamente ao marxismo contemporâneo, mas sem deixá-lo necessariamente de lado conforme recomenda Sartre: "Não se deve rejeitar o marxismo, mas reconquistar o homem no seu âmago" (2011, p. 72). Um movimento que deve ser realizado ao incorporar características microssociológicas (Piketty, 2014) capazes de se articular com as grandes matrizes e, portanto, garantir uma articulação entre a construção do objeto empírico, da teoria e da proposta metodológica.

Essa articulação entre a proposta metodológica e a construção da empiria é de suma importância para nós, pesquisadores em Comunicação, uma vez que lidamos com fenômenos por vezes tão cotidianos, mas que, nem por isso, merecem menos atenção.

Dada essa (oni)presença midiática, por vezes podemos cair em generalizações construídas na confrontação entre o conhecimento empiricamente regulado e historicamente contextualizado (Corcuff, 2015), e, para que isso não ocorra, é preciso reconhecer a complexidade desses fenômenos e dos possíveis tensionamentos que podem existir entre empiria e teoria por conta disso (Pedroso e Bonin, 2012).

Dessa maneira, uma necessária abertura no campo da Comunicação para o questionamento dos estudos realizados na área, bem como ao diálogo com outros campos e o exercício de ruptura com os pensamentos Funcionalistas e Frankfurtianos, já revisitados mas ainda presentes em muitos discursos teóricos, permitem o apoio no pensamento de Michèle Mattelart e Armand Mattelart (2004) sobre a crise na produção do conhecimento em Comunicação.

Os autores propõem que os paradigmas usados para estudar a Comunicação precisam ser repensados de modo a problematizar a informação e o direito à comunicação e também em trocas mais concretas entre local e global. Faz-se necessário pensar a produção local e, assim, abrir a um espaço global de comunicação (M. Mattelart e A. Mattelart, 2004).

As reflexões epistêmico-metodológicas devem ser buscadas através de um distanciamento crítico que possibilite visualizar como as mudanças causadas pelo remodelamento dos sistemas de comunicação afetam nossas vidas e o modo como os percebemos e nos apropriamos dos meios de comunicação. 
Maldonado (2008) também corrobora com as perspectivas trazidas por M. Mattelart e A. Mattelart ao alertar que precisamos pensar além da centralidade dos meios e de compreender a comunicação a partir dos atravessamentos presentes no campo, percebendo dessa forma a multidimensionalidade da comunicação.

\subsection{Epistemologias transformadoras como práxis: das mediações à transmetodologia}

Acreditamos que as mediações pensadas por Martín-Barbero constituem-se como um primeiro caminho para compreender que a "recepção" do conteúdo dos meios ocorre de modo não linear e com base nas relações estabelecidas entre os sujeitos e os seus referentes simbólicos. Assim, podemos perceber um sujeito ativo, reflexivo e problematizador que modela suas percepções dos meios de comunicação através do seu cognitivo, do contato com a técnica e também com o social e com a memória.

0 olhar para a autonomia dos sujeitos e os contextos concretos que os atravessam, configura-se, na nossa percepção e proposição, como um potente ponto de intersecção entre as mediações e as proposições da perspectiva transmetodológica, fundamentando e concretizando a criação de epistemologias como dimensões transformadoras para o campo da Comunicação.

Isso implicaria mudanças de diretrizes e a revisão dos estudos ainda focados no funcionalismo e no cientificismo, ampliando a abertura e a problematização das investigações da América Latina pelo exercício dialógico com os saberes populares e regionais, pensando a Comunicação a partir da cultura.

Assim, tanto a Comunicação quanto a Cultura devem ser vistas como campos de exercício de poder, de luta e também como espaço de resistência e de emergência das culturas populares. Espaços esses que sofrem mutações, aprimoramentos, atravessamentos diversos e que devem impulsionar um saber emancipador, que permita que o sujeito se transforme de maneira ativa e reflexiva e viva o seu conhecimento do mundo e do outro, alcançando, por fim, o conhecimento de si próprio.

Ambos os conceitos partem de uma decisão e posturas epistêmico-metodológicas adotadas pelo pesquisador no sentido de compreender o modo como os contextos concretos, em suas complexidades e particularidades, são fundamentais para perceber as relações entre os sujeitos e para com os meios de comunicação.

A partir dessas relações é que os arranjos e o desenho metodológicos devem ser pensados. A transmetodologia e as mediações, do modo como julgamos, acionam deslocamentos para a necessária e fundamental abertura dos estudos do campo da Comunicação para os contextos nos quais os sujeitos se situam e que interferem nas suas percepções sobre os meios de comunicação; também para o poder de decidir o que consumir ou 
não e de se apropriar dos meios não apenas como audiências, mas como produtores de conteúdo. Bem como para eleger alguns meios em detrimento de outros, por exemplo.

Martín-Barbero (2008) traz ao debate a reconfiguração das mediações a partir de uma nova constituição dos sujeitos e do contexto no qual se vinculam, assim, destaca as tecnologias comunicacionais e o seu papel histórico de mediação do conhecimento e da política. É dessa forma que as novas tecnologias abrem espaço para expor as lutas dos sujeitos pela comunicação e pela valorização de igualdades e de diferenças culturais, reivindicando o exercício de cidadania.

0 debate sobre as novas tecnologias e sobre a autonomia dos sujeitos traz, também, a recuperação do sentido de comunidade e de pertença locais, necessários para a compreensão de mundo dos sujeitos e o modo como irão se apropriar dos meios. A rede, na visão do autor, precisa ser entendida como um espaço que possibilita a ação e a emancipação, ainda que também seja marcada por contradições, como por exemplo: a disparidade de acesso e a exclusão dos que não possuem o domínio das ferramentas. A rede e as mediações reconfiguradas por ela, possibilitam pensar em novos modelos do social e novas ligações entre local e global (Martín-Barbero, 2008).

Ainda assim, não defendemos uma sobreposição ou uma visão binária entre novas e velhas mídias. Defendemos que a internet, dentro de uma perspectiva de "novas tecnologias", traz à tona o debate sobre a potência e o surgimento de espaços alternativos de comunicação e de produção de cidadania contra hegemônicos, pelos usos e apropriações particulares que podem ser dadas a ela, uma vez que, dentre tantos usos e apropriações, essas ferramentas de comunicação e de mídia podem ser usadas pelos cidadãos de modo tático a fim de potencializar e de tornar visíveis demandas que durante muito tempo foram negadas às camadas populacionais mais subalternizadas.

\section{CONCLUSÃO}

A realidade contemporânea reivindica pensar em epistemologias como dimensões transformadoras e também em métodos que possibilitem aproximação e diálogo com os sujeitos pesquisados, verificando-se que a experiência humana e os vários tipos de conhecimento devem estar unidos e serem a base da pesquisa em Comunicação social do século XXI (Maldonado, 2008). É imprescindível observarmos que a pesquisa científica é nutrida dos saberes populares, históricos, diversos e heterogêneos.

Assim, se faz preciso pensar o conhecimento científico além de lógicas institucionais e mercantilistas, compreendendo-o como emergente do contexto social. A epistemologia transformadora nos leva a perceber que a prática cientifica também se ocupa da vida e das existências, dos atravessamentos que nos são necessários e impulsionadores na trajetória acadêmico-científica (Maldonado, 2008). 
0 que podemos apreender da proposta de operacionalização dos conceitos de mediações dialogando com a perspectiva transmetodológica para a pesquisa em Comunicação na América Latina, é que, ao partir das culturas populares e do cotidiano das audiências, elas conseguem romper, de forma simultánea, com os dois grandes paradigmas do campo.

Em primeiro lugar, rompe com o funcionalismo norte-americano por inverter o sentido do controle político do povo por parte da burguesia e dar uma nova roupagem à noção de cultura de massa, reconhecendo que as relações entre as culturas populares e massivas não são unívocas nem se dão em reprodução direta e que, portanto, são complexas de tal forma que demandam um olhar heterodoxo e uma epistemologia que fuja dos maniqueísmos (Orozco, 2008).

Em segundo lugar, algo semelhante ocorre com a perspectiva crítica por essa mesma complexidade. Dado que, toda aquela noção Frankfurtiana de uma Indústria Cultural maniqueísta capaz de controlar as massas não condiz com a contemporaneidade, especialmente na América Latina, em que o binômio "produção e recepção", tão caros à concepção marxista, não fazem mais sentido quando confrontadas com perspectivas mais complexas como a das mediações e da transmetodologia.

Por isso, discutimos sobre essas duas correntes de pensamento latino-americano que têm a práxis como ponto de partida em comum e se aproximam no sentido de compreender que cada objeto carece de métodos e técnicas diferentes de análise e de observação. As combinações metodológicas, por exemplo, resultam das particularidades do olhar do pesquisador que, ao aproximar-se do sujeito pesquisado, também é afetado por suas visões de mundo, suas percepções (Martín-Barbero, 2008).

Desta forma, as mediações e a perspectiva transmetodológica, a nosso ver, se aproximam e dialogam na medida em que se constituem como dois potentes caminhos para pensar, de forma concreta, as configurações metodológicas desde a América Latina, problematizando os contextos, os múltiplos saberes, as diversidades e as diferenças dentro das pesquisas em Comunicação.

As duas concepções permitem a reflexão sobre o percurso metodológico de modo mais amplo e rompem com engessamentos e com lógicas binárias. Fazem possível compreender os sujeitos como coparticipes do processo comunicativo, construindo, assim, conhecimento a partir de uma perspectiva que esteja adequada à realidade em que vivemos. 


\section{REFERÊNCIAS}

Alsina. M. (1995). Los modelos de la comunicación. Madrid: Tecnos.

Alves, L. (2014). Comunicação, cultura e bem-público: convergências metodológicas sob desafios. Em A. Maldonado, Panorâmica da investigação em comunicação no Brasil: processos receptivos, cidadania e dimensão digital (pp. 101-121). Salamanca: Comunicación Social Ediciones y Publicaciones.

Bachelard, G. (2001). A epistemologia. Lisboa: Edições 70.

Bhabha, H. (1998). O Local da Cultura (trad. M. Ávila, E. de Lima Reis e G. Gonçalves). Belo Horizonte: Editora UFMG.

Bonin, J. (2013). A pesquisa exploratória na construção de investigações comunicacionais com foco na recepção. Em J. Bonin e N. do Rosário. (Org.), Processualidades metodológicas: configurações transformadoras em comunicação (pp. 23-42). Florianópolis: Insular.

Bourdieu, P., Chamboredon, J., \& Passeron, J. (2010). Ofício de sociólogo: metodologia da pesquisa na sociologia. Petrópolis: Vozes.

Braga, J. (2006). A sociedade enfrenta a sua mídia. São Paulo: Paulus.

Cassirer, E. (1993). El problema del conocimiento I: En la filosofía y en la ciencia modernas. San Lorenzo: Fondo de Cultura Económica.

Corcuff, P. (2015). ¿Qué ha pasado con la teoría crítica? Problemas, intereses en juego y pistas. Revista Cultura y representaciones sociales, 9 (18), 63-79.

Dussel, E. (1977). Filosofia da Libertação na América Latina (trad. L. Gaio). Edições Loyola e Editora UNIMEP.

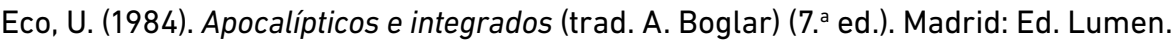

Enne, A. L.; Olivera, O. B.; Nantes, J. A. Um "ofício de cartógrafo mestiço": a proposta metodológica de Jesús Martín-Barbero como base para um estudo de caso da telenovela mexicana Rubi. pragMATIZES - Revista Latino Americana de Estudos em Cultura. UFF, Niterói, 8 (14), 62-76.

Galeano, E. (1978). As Veias Abertas da América Latina (trad. G. De Freitas). Paz e Terra, (12). Recuperado de https://copyfight.noblogs.org/gallery/5220/Veias_Abertas_ da_Am\%C3\%83\%C2\%A9rica_Latina(EduardoGaleano).pdf

Gomes, P. (2017). Dos meios à midiatização: um conceito em evolução. São Leopoldo: Editora Unisinos.

Habermas, J. (2000). O discurso filosófico da modernidade: Doze lições. São Paulo: Martins Fontes. 
Haller, R. (1990). Wittgenstein e a filosofia austríaca: questões. São Paulo: Editora da Universidade de São Paulo.

Huertas, A. (2015). Yo soy audiencia: Ciudadanía, Público y Mercado [versão kindle]. Recuperado de https://www.amazon.com.br/soy-audiencia-UOC-Press-Comuni caci\%C3\%B3n-Spanish-ebook/dp/B01G1K2VG8

Japiassu, H. (1977). Introdução ao pensamento epistemológico. Rio de Janeiro: Francisco Alves Editora.

Ladeira, J. (2016). Audiovisual, televisão, streaming: uma exploração de suas formas e estratégias. Em B. Miège et al. (Orgs.), Operações de midiatização: das máscaras da convergência às críticas do tecnodeterminismo (pp. 119-160). Santa Maria: FACOS-UFSM.

Lima, L. (2000). Teorias da cultura de massa. São Paulo: Paz e Terra.

Lopes, M. (2018). Jesús Martín-Barbero e os mapas essenciais para compreender a comunicação. Intexto (43), 14-23. Recuperado de http://dx.doi.org/10.19132 /1807-8583201843.14-23.

Luhmann, N. (2005). A realidade dos meios de comunicação. São Paulo: Paulus.

Maldonado, A. (2006). Práxis teórico/metodológica na pesquisa em comunicação: fundamentos, trilhas e saberes. Em Metodologias de pesquisa em comunicação: olhares, trilhas e processos (pp. 269-290). Porto Alegre: Sulina.

Maldonado, A. (2008). A perspectiva transmetodológica na conjuntura de mudança civilizadora em inícios do século XXI. Em A. Maldonado, J. Bonin e N. do Rosário (Orgs.), Perspectivas metodológicas em comunicação: desafios na prática investigativa (pp. 27-54 ). João Pessoa: Editora Universitária da UFPB.

Maldonado, A. (2011) Pesquisa em Comunicação: trilhas históricas, contextualização, pesquisa empírica e pesquisa teórica. Em A. Maldonado, Metodologias de pesquisa em comunicação: olhares, trilhas e processos (pp. 277-303). Porto Alegre: Sulina.

Maldonado, A. (2013). A perspectiva transmetodológica na conjuntura da mudança civilizadora em inícios do século XXI. Em A. Maldonado, J. Bonin e N. do Rosário (Orgs.). Perspectivas metodológicas em comunicação: Novos desafios na prática investigativa (pp. 31-57). Salamanca: Comunicación Social Ediciones y Publicaciones.

Martín-Barbero, J. (1987). De los medios a las mediaciones. Comunicación, cultura y hegemonia. Barcelona: Gustavo Gili.

Martín-Barbero, J. (1988). Procesos de Comunicación y Matrices de Cultura: Itinerario para salir de la razón dualista. México: Gustavo Gili. 
Martín-Barbero, J. (1998). De los medios a las mediaciones. Comunicación, cultura y hege monia (5a. ed.). Bogotá: Convenio Andrés Bello. [Obra com a segunda introdução].

Martín-Barbero, J. (2008). Pistas para entre-ver medios y mediaciones. Revista Anthropos/ Huellas del conocimiento, (219), 43-48.

Martín-Barbero, J. (2013). Dos meios às mediações (7. ed.). Rio de Janeiro: UFRJ.

Mattelart, A.; Mattelart, M. Pensar as mídias. São Paulo: Edições Loyola, 2004.

Mignolo, W. (2006). Os esplendores e as misérias da "ciência": colonialidade, geopolítica do conhecimento e pluri-versalidade epistêmica. Em B. Santos, Conhecimento prudente para uma vida decente. São Paulo: Cortês.

Mignolo, W. (2008). Desobediência epistêmica: a opção descolonial e o significado de identidade em política. Cadernos de Letras da UFF, (34), 287-324.

Morawicki, K. (2016). Matrices teóricas y políticas en el campo académico de Comunicación y Educación en Argentina. Revista Actas de Periodismo y Comunicación, 2(1). Recuperado de http://perio.unlp.edu.ar/ojs/index.php/actas/article/view/4023

Morin, E. (2008). $O$ método 3: 0 conhecimento do conhecimento. Porto Alegre: Sulina.

Norris, C. (2007). Epistemologia: Conceitos-chave em filosofia. Porto Alegre: Artmed.

Ollivier, B. (2008). Medios y mediaciones. Revista Anthropos/Huellas del conocimiento, (219), 121-131.

Orozco, G. \& Miller, T. (2018). A televisão além de si mesma na América Latina. Matrizes, 12(3), 59-75. Recuperado de www.revistas.usp.br/matrizes/article/ download/153196/149817

Ortiz, R. (2008). Caminos de la mediacion: Comunicación y culturas em América Latina. Revista Anthropos/Huellas del conocimiento, (219), 132-135.

Pedroso, D. e Bonin, J. (2012). Metodologia no processo investigativo: a construção da arquitetura teórico-metodológica de uma pesquisa de recepção cinematográfica. Interin, (13), 1-18.

Peruzzo, C. (2016). Epistemologia e método da pesquisa-ação. Uma aproximação aos movimentos sociais e à comunicação. Em Encontro Anual da Compós, Goiânia. Anais..., Associação Nacional dos Programas de Pós-graduação em Comunicação. Recuperado de http://www.compos.org.br/biblioteca/epistemolo giaemétododapesquisaação...ciciliaperuzzo.modelocompos2016._3270.pdf

Piketty, T. (2014). 0 capital no século XXI. Rio de Janeiro: Intrínseca.

Piza, S. e Pansarelli, D. (2012). Sobre a descolonização do conhecimento - a invenção de outras epistemologias. Estudos de Religião, 26(43), 25-35. 
Popper, K. R. (1975). Conhecimento objetivo: uma abordagem evolucionária. Belo Horizonte: Ed. Itatiaia/São Paulo: Ed. Universidade de São Paulo.

Rincón, 0. (2016). 0 popular na comunicação: Culturas bastardas + cidadanias. Trad. Ciro Lubliner. Revista Eco Pós, 19(3), 27-49. Recuperado de https://revistas.ufrj.br/ index.php/eco_pos/article/download/5420/3994

Rossetti, R. (2016). Mudanças teóricas nas trajetórias de funcionalistas e frankfurtianos. Em Encontro Anual da Compós, Goiânia. Anais... Associação Nacional dos Programas de Pós-graduação em Comunicação. Recuperado de http://www. compos.org.br/biblioteca/2016mudançasteóricascompos_3364.pdf

Santos, B. S. (2006). A gramática do tempo: para uma nova cultura política. São Paulo: Cortez Editora.

Sartre, J. P. (2011). Crítica de la razón dialéctica. Buenos Aires: Losada.

Schlesinger, Philip. (2008). Huellas del conocimiento en J. Martín-Barbero. Revista Anthropos/Huellas del conocimiento, (219), 104-112.

Sodré, M. (2015). A comunicação eletrônica é epistemóloga. Entrevista de Muniz Sodré concedida à R. G. Revista Parágrafo, 1(3), 120-127. Recuperado de http:// revistaseletronicas.fiamfaam.br/index.php/recicofi/article/view/289

Sodré, M. (2016). Mídia, ideologia e financeirização. Oficina do Historiador, Porto Alegre, EDIPUCRS, 8(1), 134-157. Recuperado de http://revistaseletronicas.pucrs.br/ojs/ index.php/oficinadohistoriador/article/view/18591

Torrico Villanueva, E. R. (2016). Hacia la Comunicación decolonial. Serie Integrar. Volumen $N^{\circ}$ 2. Sucre: Universidad Andina Simón Bolívar.

Vieira, F., Coêlho, T., e Marques, A. (2016). 0 rosto na imagem, a imagem sem rosto: apontamentos para pensar outramente a relação entre estética e política. Em Encontro Anual da Compós 2016, Goiânia. Anais..., Associação Nacional dos Programas de Pós-graduação em Comunicação, 2016. Recuperado de http:// www.compos.org.br/biblioteca/marquestemplatecomposautoria_3289.pdf.

Vieira, E. \& Silva, T. (2018). Monitorando audiências televisivas nas mídias sociais. Em T. Silva, J. Buckstegge, P. Rogedo. (Orgs.), Estudando Cultura e Comunicação com mídias sociais (pp. 315-335). Brasília: Editora IBPAD.

Wallerstein, I. et al (1996). Para abrir as Ciências Sociais. (Comissão Gulbenkian para Reestruturação das Ciências Sociais). São Paulo: Cortez Editora.

Wolf, M. (2008). Teorias das comunicações de massa. São Paulo: Martins Fontes.

Zalamea, F. (2008). La inteligencia del tránsito. Revista Anthropos/Huellas del conocimiento, (219), 71-78. 